This item was submitted to Loughborough's Research Repository by the author.

Items in Figshare are protected by copyright, with all rights reserved, unless otherwise indicated.

\title{
Trauma, discourse and communicative limits
}

PLEASE CITE THE PUBLISHED VERSION

http://dx.doi.org/10.1080/17405900903180970

PUBLISHER

Routledge (@ Taylor \& Francis)

VERSION

AM (Accepted Manuscript)

LICENCE

CC BY-NC-ND 4.0

REPOSITORY RECORD

Pickering, Michael, and Emily Keightley. 2019. "Trauma, Discourse and Communicative Limits". figshare. https://hdl.handle.net/2134/5419. 
This item was submitted to Loughborough's Institutional Repository (https://dspace.lboro.ac.uk/) by the author and is made available under the following Creative Commons Licence conditions.

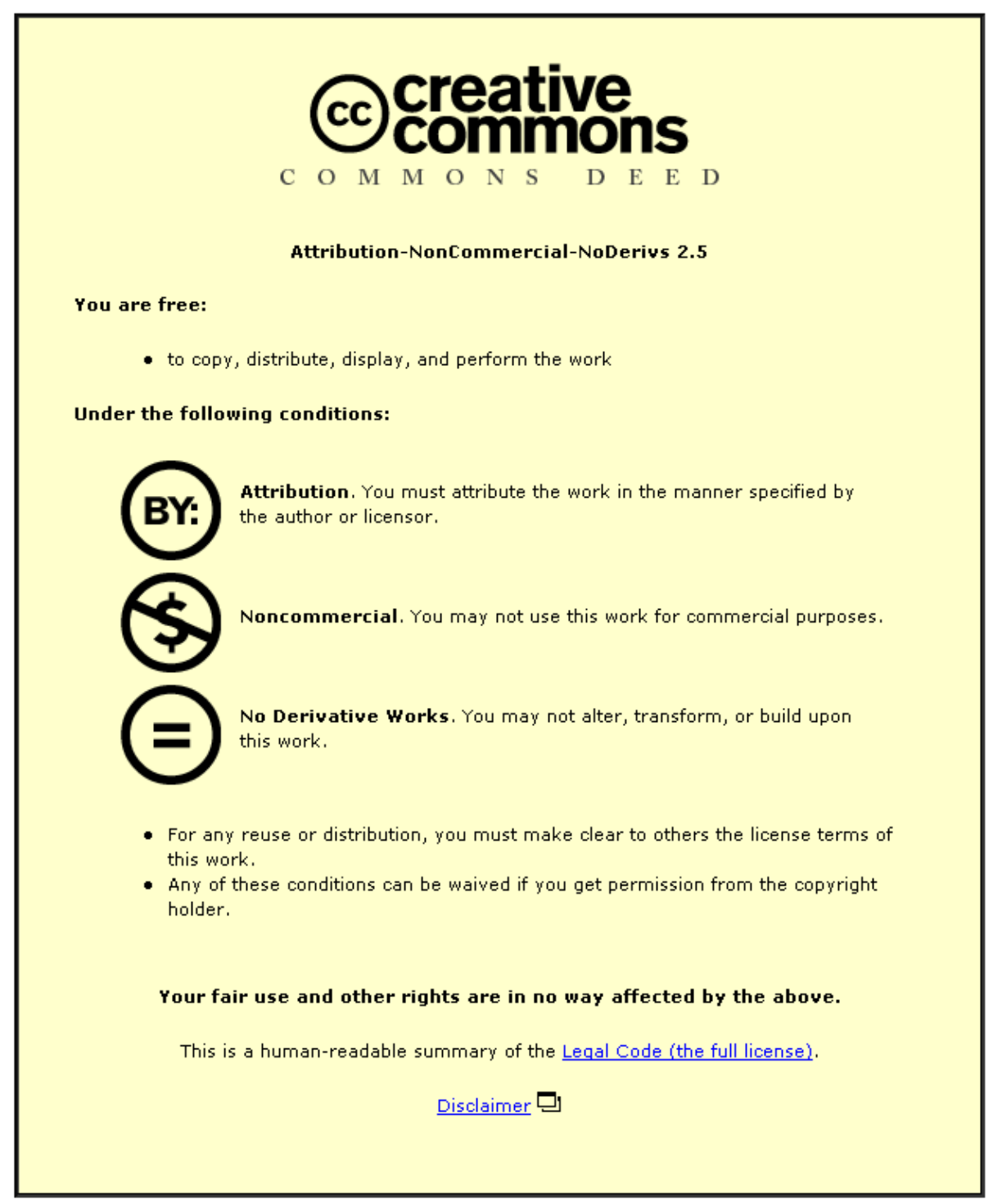

For the full text of this licence, please go to: http://creativecommons.org/licenses/by-nc-nd/2.5/ 


\title{
TRAUMA, DISCOURSE AND COMMUNICATIVE LIMITS
}

\author{
MICHAEL PICKERING AND EMILY KEIGHTLEY
}

\begin{abstract}
Trauma is a term that is widely used in memory studies, along with a number of other academic fields and disciplines. This article takes issue with its loose and indiscriminate application. Such application generates an unresolved paradox: trauma is associated with memories of events that are uncontrollable, yet large-scale commemorative practices or processes of social reconciliation assume that experiences of these are controllable, amenable to being assimilated into narrative form and so available for rhetorical purposes. Following an examination of this paradox, the article looks in detail at two examples of experience involving painful memories of two kinds those which have become integrated into relatively easily told stories, and which can then involve rhetorical work, and those which have not become woven into a life-narrative and so are not available for such work. The article also considers some of the methodological and analytical problems that occur when traumatic or painful memories arise in the course of sociological fieldwork.
\end{abstract}

Keywords: Trauma, pain, memory, history, narrative, life-story, rhetoric.

\section{Questions of Applicability}

Over the past quarter century, memory studies has emerged as a vibrant interdisciplinary field of study with a distinctive set of preoccupations and concerns. In many ways it has developed by proceeding outwards from individual memory and concentrating on broad dimensions of social memory and the politics of commemorative or other forms of remembering, especially those channelled through modern communications media. The explanatory focus has generally been on how these forms of remembering operate as public representations of the past, how they constitute a range of cultural resources for social and historical identities or how they privilege particular readings of the past and subordinate others. Despite these advances, a key question remains a major stumbling block. This is the question of how individual and collective modes of memory are realised via quite distinct processes, even if they inform and interact with each other. In some ways this is not surprising, given the complex issues that are involved, not least of which are those involving conceptualisations of the individual and of various forms of collectivity, such as the social group, community or nation. In other ways it is surprising that little consensus has emerged as to the relative position and status of the individual and the collective within memory studies. It is, after all, the relation between the two that is at stake in so much of what memory studies attends to. This involves large and difficult questions, and in this article we seek only to make a modest contribution to the question of their relative position and status within the dynamics of their interrelationship by attending to what is for us an avoidable problem. The problem is the overblown conception and at times indiscriminate use of the term trauma in memory studies. Our 
argument is that the use of this term requires greater care and consideration than it is usually given.

We argue this not because of the position of centrality which the term has acquired in memory studies, but because in memory studies there is often a huge but unexplained leap from its clinical association with individual cases of pain and suffering to its use with reference to collective experience and collective memory. ${ }^{1}$ It is assumed that there is some level of continuity or connection between the problem of a terrifying and shocking event that lies hidden in the subterranean recesses of a victim's psyche and the problem of how collectively tragic events are represented (or not) in communications media or in acts of public remembrance. The assumption underlies various loose uses of the term, as for example when phrases like 'traumatised societies' and 'screen trauma' are introduced with little, if any conceptual elaboration or clarification. ${ }^{2}$ For us, this demands a closer look at the term trauma and its applicability to a range of diverse and in some ways quite disparate phenomena. In doing this, the first point to note is that the term trauma acquired its most significant conceptual meaning in modern times from psychology and its two therapeutic branches of psychoanalysis and psychiatry. Its meaning in this respect has a very particular consequence. If we say that remembered experience is constitutive of our successive selves as these inform our sense of identity through time, what is psychologically distinctive about traumatic experience is that it leads to a denial or severe inhibition of this process. The repression of memory as a selfprotective response to trauma then makes forgetting rather than remembering decisive for the human subject. Memories which are submerged in this way may find expression in screen memories, or may seem suddenly to erupt in terrifying flashbacks, and when minds are troubled and disturbed, what connects traumatic experience and repressed memory is the inability to assimilate the experience into conventional narrative, to give it expressive form and make it storyable. This can lead to a cumulative exacerbation of interpretive difficulty and disruption for the individual subject involved, for it is not just the originating pain and hurt that causes trouble within a life story, but also how this plays 'a decisive role in a person's perception of life afterwards, interpretations of subsequent events, and ... memories of preceding experiences' (Leydesdorff, 1994: 15). It is because of such continuing repercussions that traumas prove to be abiding sources of suffering or, as William James (1894) once put it, 'thorns in the spirit' with which the human subject must struggle to live.

This means that the primary conceptual value of the term trauma is its reference to the severe difficulty of coming to terms with a shocking or painful event or an enduring series of such events in an individual's experience, along with the consequences of this in someone's subsequent life. We can of course distinguish between the resilient handling of traumatic events, leading to stronger personalities and post-traumatic growth, and less

\footnotetext{
${ }^{1}$ For valuable discussion and application of the term in memory studies, see Antze and Lambek (1996), Bennett and Kennedy (2003), Caruth (1995, 1996), Felman and Laub (1992) La Capra (1994, 1999, 2001), and Tal (1996).

2 Jacobs (2008: 211) refers to 'traumatised societies' in an article on the representation of women at Auschwitz, and Zylinska (2005: 76) talks of 'screen trauma' in discussing the media theatricalisation of the events of $9 / 11$.
} 
successful responses to severely disruptive events which lead to mental disturbance and the psychic problems associated with post-traumatic stress disorder (see Bridgers, 2005 for this distinction). The conditions then identified with repressed memory can be broached by psychoanalysis or other therapeutic processes, but the characteristic symptom of trauma and its associated forms of disorder remains the individual subject's inability to remember the past in a relatively coherent manner - coherent, that is, for the sake of a recognisable continuity of self - and to articulate this in narrative form to others as an integral aspect of everyday interaction. Trauma profoundly disrupts the capacity to connect back with the past and make it validly usable in the present, though of course responses to trauma and their subsequent manifestations range considerably in severity and so vary widely in how they may be observed.

Such variation does not, however, provide a licence for the indiscriminate use of the concept of trauma. This is widely evident in memory studies. The problem begins when the concept, and Freud's notion of 'working through' towards the healing stage of giving voice to an individual subject's traumatic past, are extended to its applications at broad collective levels of violence and suffering, involving huge agglomerations of people (nations, ethnic categories, entire genders). Two questions immediately follow: In what sense is trauma and its attendant disorders applicable to such vast groupings, and in what ways are extrapolations from individual suffering being made? In trauma studies and culturalist versions of psychoanalysis, the underlying premise is that links can be examined 'between the inner world of memory and the external world of historical events by focusing on the experience of pain', and that 'nations - like individuals - must work through grief and trauma' (Misztal, 2003: 141). This premise is untenable because pain cannot provide such links - it can only be experienced physically by individual bodies and because nations in themselves cannot remember any more than they can think or feel. This is to take nothing away from attempts to reconcile immense collective suffering with personal tragedies, or to seek ways of respecting the intensity of individual experience at a collective level, particularly where cases of gross abuses of power are involved. Nor is it to cast doubt on the ways in which attempts at redressing collective injustice, in national and international cases of forced labour, mass rape, torture or genocide, are in themselves of enormous value, for ethical and political as well as historical reasons. The objection is instead to the profligate ways in which the concept of trauma is being deployed and the damage this does to our understanding of the relations between the individual and the collective.

Of course, what enables the extension from the individual to the collective is metaphor. ${ }^{3}$ The question that follows from this is whether applying the concept of trauma to collective suffering has any valid meaning in itself rather than solely as a rhetorical trope. Used metaphorically, the term trauma is certainly powerful and can be said to convey, at least in some measure, the immensity of suffering that is involved in war crimes or systemic racial oppression. What is at issue here is not the validity of metaphor as a figurative device, for metaphors are integral to expressive form and often the first

\footnotetext{
${ }^{3}$ We use the term metaphor here as a meta-category to include such figures of speech as metonym, synecdoche, simile, allegory and symbol, as well as metaphor as a more specific device of comparative substitution.
} 
step to advances in conceptual thought. The troublesome issue is that of reading off from individual trauma into broad institutional spheres and public discourses where what is at stake are actually remembered events represented as traumatic for the sake of reparation or reconciliation, and not the problem of the amnesiac self. In a discussion of the complex issue of how to deal with individual and collective remembering in memory studies without recourse to binaries of public and private, or psychic and social, Susannah Radstone cites Christopher Colvin's essay on Truth and Reconciliation Commissions (TRCs), such as that in South Africa, in which he complains that 'terms associated with personal memories of suffering are being deployed to describe the history of a nation' (2005:143). In the consequent 'therapeutic historiography', the 'key events of history are portrayed as a series of traumatic events', as if trauma is 'the hidden hand that moves history' (Colvin, 2003:159). History knows no such hand, hidden or otherwise, and can much more adequately be described as an interlinked pattern of intended and unintended consequences. In light of this it seems entirely reasonable for Colvin to conclude that 'psychotherapy is embraced privately by many as a means of individual recovery, but not as a guide for how the history of apartheid should be written' (Colvin, 2003:166). If the promise of memory studies is that of overcoming the memory/history divide, this is not the way that promise will be realised.

Conceptual vocabularies devised in the attempt to improve our understanding of psychic damage are ill-suited to the sociological analysis of collective forms of commemoration, negotiation of pasts poisoned by racist oppression, or media reconstructions of controversial historical events and episodes ${ }^{4}$. The use of such terms as trauma in ways that go far beyond personal memory is nevertheless so much a part of recent directions in memory studies that it is commonplace and uncontentious. There is an enormous assumption here. As Radstone puts it, the 'recent burgeoning of work on traumatic memory and testimony to suffering may be at risk ... of assuming that terms best suited to the description of affects felt and not felt by an individual, or in play between individuals, can be applied to analyses of the diverse articulations of memory in the public sphere' (2005: 147). This has in fact become a predominant mistaken tendency in memory studies, involving an excessive stretching of memory in areas beyond the individual, and a general lack of explanation about what this analytical stretching may involve, so that social, cultural, public or national memory are terms that are usually taken-for-granted and so under-conceptualised. This tendency could be said to be an over-reaction to another analytical pitfall: that of asocial individualism, involving either an excessive stretching of individuality and an occlusion of the continual interaction between the individual and historically specific social institutions and cultural formations, or an idealised sense of memory as raw, pure or unmediated. These tendencies are opposite sides of the same coin, and both obstruct the effort to rethink the relations between individual and collective memory and avoid the usual entrenched binaries in the process, never mind also reconceiving the conventional oppositions between memory and history and their different temporalities.

\footnotetext{
${ }^{4}$ There are of course other cases where the applicability of psychological and/or psychoanalytic terms for collective experiences and memories should be called into question and interrogated. These are beyond the bounds of the present article.
} 
It could of course be said that advancing the notion of collective trauma in memory studies is a response to recent attempts to discursively construct new forms of subjectivity around the notion of trauma. They are central to what Roger Luckhurst calls traumaculture, the characteristic phenomena of which range from multiple personality disorder, recovered memory therapy and the already mentioned post-traumatic stress disorder, through legal disputes over the definition of nervous shock, to contemporary art (Gillian Wearing, Tracey Emin, Tracey Moffat), shockumentaries, pathographies and misery memoirs. The forms of subjectivity attendant on these phenomena are internally contradictory in that their projection outwards is based on the notion of a damaged self that 'cannot remember itself to itself; it has no cohesive narrative, only fragments loosely linked through ominous occlusions'. They draw upon the powerful semantics of the term trauma but remain paradoxical, for organising an identity around trauma 'is to premise it on exactly that which escapes the subject, on an absence or a gap’ (Luckhurst, 2003: 28).

Reference to traumatic subjectivities may therefore help to explain the tendency in memory studies of excessively extending notions of psychic disturbance into collective spheres, but it does not exonerate it precisely because it is itself part of the formation of of traumaculture, and so has been insufficiently critical of its varied phenomena. It has too often endorsed, and at times even celebrated, 'the allure of traumatic identification' and the extension of traumatised identities into 'privileged sites of communality' that have 'to be compulsively re-staged because there are no longer any theoretical means to process trauma ... Compulsively, the shock is renewed but without any advance in comprehension' (ibid and 39).

The stalled understanding involved in this has various consequences, but among the most serious is the lack of recognition that what is lost in the transition from individual to collective uses of the term trauma is the integrity of subjective experience. Its application as an explanatory grid for problematic or painful national and other collective pasts diminishes the status of the concept in therapeutic discourse. There it has the potential to contribute to a subject's ability to overcome neurotic symptoms through reconstituting certain past experiences and settling affective disturbances. When applied to collective pasts, the finite meanings and characteristics of traumatic experience become blurred and the specific nature of the pain and distress which underpins traumatic experience is disregarded. Pasts which are painful but nevertheless knowable are routinely analysed using the framework of trauma. What is then lost is the notion of trauma as involving experiences so radically disruptive to the self as to be inassimilable when using the social and cultural resources at our disposal. Instead, trauma becomes an overused and imprecise descriptor for any past experience of a difficult, problematic or contentious nature. There is a failure to distinguish between some losses which may be traumatic and others which are not and, as a result of the faulty assumption that 'all history is trauma', we lose any sense of the distinctiveness of the experience of radical loss. The results are serious. They either render the experience of 'trauma', as recounted narrative, a necessary element in the constitution of selves, or facilitate the appropriation, as symbolic capital, 'of particular traumas by those who did not experience them' (Hacking, 2002: 18-19; La Capra, 1999: 712). 
For an individual suffering from traumatic experience there is a marked difficulty, sometimes profound, in making the experience storyable and knowable. In contrast, where trauma is characterised as a collective experience, accounts of the injurious collective experience are already manifest and made knowable through communicative and representational practice. This central difference is routinely overlooked. For example, Arthur Neal has suggested that the enduring effects of trauma on the individual resemble the enduring effects of a national trauma 'in collective consciousness'. He suggests that if individual trauma involves a range of 'maladaptive responses', including eating disorders and impaired memory, responses to national trauma likewise involve fear and feelings of vulnerability, while damage to the social system generates national discourse 'directed toward the repair work that needs to be done' (1998: 4-5). Bizarrely, this is the opposite of trauma and its consequences, for it emphasises the possibility of reconciliation of an event or experience to conditions in the present. Neal suggests that the primary difference between individual and collective trauma is that collective trauma is shared with others (1998: 4). But in order to be shared, painful experience has to representable, communicable, in some way knowable. Neal's usage contravenes the very criteria by which trauma is defined. According to Cathy Caruth, trauma is not 'locatable in the simple violent or original event in an individual's past, but rather in the way its very unassimilated nature - the way it was precisely not known in the first instance returns to haunt the survivor later on' (1996: 4). For this reason, 'the impact of the traumatic event lies precisely in its belatedness' (Caruth, 1995: 8).

Specific cases of trauma do of course acquire definite social and cultural features. The experience of many women raped during the armed conflict in the Democratic Republic of Congo, for example, is traumatic not only because of the violence of the event itself, but also because of the disruption of social norms, conventions and values surrounding sexual relations and the consequent social stigmatization. But trauma is not reducible to these features. In making this point, we take issue with Jeffrey Alexander's claim that locating trauma in individual experience constitutes a naturalistic fallacy which assumes that events themselves are inherently traumatic. It may or may not, depending on the analyst. Alexander's counter-assumption that any collective past, real or imagined, can be socially constructed or reconstructed as a trauma, either in real time or after the event, simply cannot be substantiated (Alexander, 2004: 9-10). Coherent narrative reconstruction is precisely what is difficult for those suffering from trauma. By disregarding this defining characteristic of trauma, Alexander broadens the concept of trauma to the extent that almost all specific psychological meanings have been evacuated from it.

The unsuitability of the discourse of trauma to post-hoc cultural representation of an event or experience has not gone unrecognised. Kristian Gerner's account of collective practices of remembrance and of cultural representation associated with the Hungarian Trianon Treaty, for example, acknowledges the inappropriateness of the term trauma for organised cultural expressions of the historical past. Although characterising the event itself as a trauma, Gerner's explicit rejection of the concept of trauma as able to provide an analytical framework is commensurate with our assertion that trauma is not easily transposed into the realm of social communication and cultural representation (2006: 
105). The concept of trauma deals with the rhetorical failure of memory, rather than with remembrance's effective conduct as a mode of making sense of the past in relation to the present and future.

Our argument then is threefold. Firstly, the concept of trauma has been used in a loose and cavalier manner in memory studies. Too often a metaphor is paraded as a cultural given. When it is taken up in connection with national histories, this is done with little respect for the acute pain and distress that lies hidden under the traumatic disorder, and little consideration of what is lost in the transition from individual psychology to collective experience. Individual psychic disturbances should be situated in social and cultural context, but the traumatic experience should not be transposed wholesale into the collective realm. This would be to counter naturalistic fallacy, where it occurs, with sociologistic fallacy. Secondly, if trauma is the name for events or experiences which are retrospectively uncontrollable, and so not amenable to being recognised as memory or articulated as narrative, the notion of traumatic memory as having rhetorical value for memory studies is illegitimate. To be rhetorical assumes that such memory is controllable, and can be rationally managed in human discourse. Trauma is instead a term for the lack of such control. Thirdly, the concept of trauma cannot be applied to all problematic or painful experience. It is only where the past is inaccessible, inassimilable and unavailable for the task of making sense of experience that the concept of trauma is a relevant analytical device. It is inappropriate to talk of effective representations or accounts of the past as traumatic when they are functioning successfully to make the past knowable and usable. It is however entirely appropriate to use the critical framework of trauma to account for silences, losses and failures in representing or giving an account of the past. It is to this application that we now turn.

\section{Questions of Trauma}

We wish to consider in detail two specific examples of painful remembered experiences drawn from in-depth interviews with two different women in order to demonstrate the ways in which traumatic experience and accounts of it are distinct from those accounts which can be characterised as painful memories where successful integration of the event into a life story has occurred. The extracts are from a larger research project involving a series of interviews with men and women of different ages, ethnicities and social backgrounds about the ways in which they construct memories of their pasts in narrative form. This approach draws on the broader tradition of using life stories in psychological and sociological investigations of the construction and performance of identity. The creation, negotiation and exchange of life stories is commonly understood as an expression of self and, as data, life stories 'serve as a model for a unified linguistic analysis - one that moves from the level of the individual construction of sentences, through the form of narratives and the social negotiation of narratives, up to the level of belief systems and their history' (Linde, 1993: 3; see also Atkinson, 1998; Bertaux, 1981; Plummer, 1983). By analysing the discursive features of the two accounts, specific judgements can be made about the extent to which the painful experience can be 
considered traumatic for the interviewees in the present ${ }^{5}$. The analysis also provides an illustration of the utility of trauma as an analytical device where individual experience can be kept in view by exploring specific discursive constructions of the past, but allowing the particular social and cultural conditions informing these discursive acts to be recognised and assessed.

The first interviewee is a working-class British woman in her early sixties who is giving an account of her experience of marriage to a man suffering from severe mental illness and his subsequent death several years previous to the interview:

IRIS: I left the house at Beresford Road and vowed never to go back. I had to leave him in the end. And it was just like y'know 'Great Expectations' and nothing had changed. And when he died, I had to go up to the house, nothing had changed. There were no cleaning or anything, or anything, done. Nothing! Nothing! It were just, nothing had changed. I said to my girls, 'I'm never going back up that house'. There's too many bad memories. By God there were. I said 'I'm never going back up'. But when he died I had to go up. Clear it out. I never ask help, but said 'I've got to have help this time. I can't do it'. Oh it was awful. It brought it all back. I wish the bugger would go, but it won't. Nothing had changed. It was if I'd just gone, that day. It were absolutely filthy. So where was social services and all his care workers? So I sold that. I was in a flat. I had to move out of that flat because they put the druggies up the top. So I had to go and lodge with this chap. Very kind of him. And got this. And that was it. It wants a lot doing to it, but it's... it's mine.

INTERVIEWER: Has moving into a house that's just yours helped leave some of those less pleasant memories behind?

IRIS: Sometimes they come. Our girl, she brought her dad's television. I said 'I don't want it in the house. I'm sorry but I don't want it'. She said 'oh' she says 'mam'. I says 'no! I don't want it'! In't it strange? I never thought I'd do that. I said 'No. I don't want it'. The worst part of it was, cos he had a heart attack, so they found him, so I had to go to the, they all knew where I lived, I left everything, his carer's knew where I lived, I still went in to look after him. And I get this call, 'could I go to the police

${ }^{5}$ At this stage of the research interviewees were selected through networks of contacts initially established through local reading groups. Interviews were conducted based on the theme of remembering in everyday life and were unstructured, mostly lasting between one and two hours. They were transcribed verbatim and key themes were identified across the interviews. Transcripts were broken into thematic groupings, including the descriptions of painful episodes in life stories. The two segments of transcript selected for this article were then subjected to linguistic and narrative analysis, attending to the organization of the talk as well as the content, in order to assess the ways in which meaning was discursively constructed by the speaker (or not). Particular attention was paid to such discursive features as repetition, disjointed sentences and the confusion of tenses, which signaled difficulty in communicating because of the pain experienced in the past. For guides to narrative analysis, see Kohler Riessman, 1993 and 2008, and Elliott, 2005. 
station', I said 'what on earth for', they said 'concerning your husband' so I said 'I bet he's not taking his medication', which he didn't, so he says 'it's a bit more serious than that' so I says 'oh, like what' and he says 'oh, we'll send the police down'. Well, I were on me own in a little flat, you can imagine. Then they told me and they said 'Well, can you get?' and I says 'No, I can't', I said 'well I've got to tell our girls'. Cos I tried to keep everything from 'em. And I suppose, as our Ruth said: 'Mum, we knew everything what were going off'. But you try to shield em from...this and then, then I had to go to um, County Courts to get his possessions. I were all at sixes and sevens. I'd got to do this. I said 'I can't write that'. Buggers wouldn't help me. I've never forgotten that. I said 'you'll have to help me... how to spell it cos I got...'. So it's all spelt dreadful and I've never forgotten that. And all there was, was his driving license, hundred and something pound, that were it. Oh it were awful. To go in that house. It were like 'Great Expectations'. Nothing had changed. Not chucked anything away.

Iris's account winds around a series of significant incidents associated with her husband's death: her return to the marital home where 'nothing had changed'; the sorting of her husband's possessions; her difficult interaction with local institutions. A number of discursive features in the extract suggest that it offers an example of a severely disturbing and only partially assimilated recollection. The narrative is disjointed and out of any logically progressive, chronological sequence, with the respondent jumping between episodes without warning or explanation. For example, in the final lines of the extract she shifts precipitously from her difficulties in filling in the requisite forms to the experience of returning to her marital home, while earlier in the transcript she moves suddenly from her daughter bringing in her father's television set and her husband's cause of death. Her sentences are not fully formed and in some instances go unfinished, making their meaning somewhat elusive. These features signal the difficulties that she has in articulating her experience according to conventional linguistic rules and narrative codes.

The analysis of therapeutic discourses has already established that emotionally involved narratives are significantly different in form to those in which experiences have been worked through and the meanings of past events have been stabilised (Wodak, 1986; 1996). This recognition can be developed further in accounting for the nature of these differences in in cases of trauma. The example here is not of unknowable trauma but of painful experience with traumatic features. Iris's memories are to a degree uncontrollable, as is evident from the jagged, dislocated form of her narrative. In response to a question about leaving painful memories behind, she responds with 'sometimes they come'. She is not authoring herself here as an active agent in control of her memories but rather handling dreaded involuntary memories as best she can: " $n o$ ! I don't want it'! In't it strange?" She expresses surprise at her own response, not for rhetorical purposes but because 'I never thought I'd do that'. The memory of her actions remains irreconcilable with her sense of continuous selfhood as she comments on her own inexplicable response. The fragmented recollection is evidence of disruption to her ability to narrativise her self. 
Repetition is a key characteristic of the extract. Iris does this particularly with reference to returning to her marital home to find 'nothing had changed'. The stark, still shocked quality of this stands in place of the reflexive rationalisations of experience characteristic of undisturbed remembering; instead, the experience returns in a visceral manner, remaining irreconcilable and unexplainable in narrative form (Freud, [1920]2001: 18). The account is certainly comprehensible, but at the same time deeply troubled.

A key aspect of this is Iris's use of literary metaphor to make sense of her experience. The example she draws on refers to Dickens's character, Miss Havisham, who maintains her house exactly as it was at the time she was jilted on her marriage day. The comparative reference is apt in capturing the sense of all the clocks in the house having stopped and 'every discernible thing' from the past being 'covered with dust and mould, and dropping to pieces' (Dickens, 1965: 112-13). It clearly provides some help in working through the traumatic features of her experience, yet the insistent repetition that nothing had changed seems to be what counts, with the unelaborated metaphor being of stock convention and limited explanatory value.

A further traumatic feature of Iris's account is her inability to sustain an organized distinction between past and present. Dominick La Capra regards this as characteristic of 'post-traumatic situations in which one relives (or acts out) the past', and in which 'distinctions tend to collapse, including the crucial distinction between then and now wherein one is able to remember what happened to one in the past but realize one is living in the here and now with future possibilities' (1999: 699). The shrouds of the past obstruct this realization and, within the account, blur temporal markers and boundaries between past and present. Iris's frequent shifts between present and past tenses, even within the same sentence, alongside her extensive use of reported speech, show that rather than narrating the event from the distanced perspective of the present, past and present are at certain points collapsed into one another and at certain times she is tossed helplessly back into the harrowing experience of ten years or so ago. This is akin to, though less spectacular than, the flashbacks which return to haunt those experiencing post-traumatic stress disorder.

Iris's experience of a past autobiographical episode which continues to be experienced as deeply troublesome was compounded by her social exclusion. Her difficulty in writing caused problems with filling in the requisite institutional forms after her husband's death and the incomprehensible nature of these forms has contributed to, or become indicative of, her difficulties in making sense of the experience. In later parts of the interview she refers to the social stigma attached to mental illness and the social isolation it caused. Her experience of social exclusion intersects with the experience of her husband's illness and death, revealing her lack of preparedness for the combination of events surrounding her husband's death. This may further explain why the event was experienced as so radically disruptive. Its quality of profound disturbance was situated not only in the event itself but also in the socially marginalized location from which she experiences it. She is both alienated from social modes of communication (written 
language) and socially excluded on the basis of the stigma attached to mental illness. Topping it all, she does not have sufficient social and cultural tools to make sense of, or effectively 'story', her experience.

In contrast to Iris's account the second extract is from an interview with a middleclass British woman who gives a relatively calm and coherent narrative of the death of her first-born child.

FIONA: Well I'll tell you but you're not to burst into tears at this story. My first baby died at seven months. I think she was destined to die right from the beginning but I didn't know that at the time. And when I had Georgina eighteen months later, I know I wanted to record much more because I'd only got a few pathetic photos of Victoria, so I probably took more than the average person. I recorded lots and lots of their intimate moments of their growing up for a long, long while. But A, they're not changing so rapidly now; $B$, they don't live at home and they don't belong to me if you like. You know, they're living their own lives. I don't need to. I don't know if I've got obsessive amounts of photos of them growing up, I might have because of that. Although I basically documented lots and lots of their childhood.

INTERVIEWER: Do you visit those memories of Victoria often?

FIONA: Very rarely. It's not necessary at all. When I say don't burst into tears, because it would be wasted. It was very sad. But I don't have any regrets about it. It was a very steep learning curve. It was a very valuable experience. I was devastated at the time but I went on to have two happy healthy children. It would be much more tragic if I hadn't. When you have two healthy children you don't have time to consider one that dies. It was a very important experience in my life. The only times I would possibly think about them now. If I think how old Georgina is, it occasionally pops into my head. Or if I knew someone who was going through a similar experience I would, I hope, be brave enough to share it if they needed to talk to somebody about it. But I don't need to do it myself. It was ghastly in lots of ways. I won't go into details because it would be hard for you.

Despite the painful subject matter of Fiona's account, it is characteristic of an effectively memorised experience rather than one with continuing traumatic features. The chronological structure of the account and the detailed explanation, rationalisation and interpretation of the experience in retrospect shows that the 'ghastly' experience has been successfully assimilated into later periods of her life using the discursive resources available. The utility of social frameworks determining the meaning and performance of motherhood are drawn on as Fiona positions herself in the narrative as a successful mother with reference to her two subsequent 'happy healthy children'. The description of her first daughter's death as a 'learning curve' is also constructed with reference to social conventions of motherhood. The repository of the family album and Fiona's deliberate intent to fill it with as many intimate moments of her subsequent children's childhood as 
possible help shore up the awful breach of her previous loss, and compensate for the 'few pathetic photos' she has of her first daughter. The experience of losing her first daughter is no longer configured as a tragedy because of her subsequent successful maternal performance. In contrast to Iris, Fiona finds the available social frameworks of meaningmaking, such as that of motherhood, adequate and adaptable enough to deploy as discursive devices in order to construct the devastating loss in a conventional and meaningful narrative form. By positioning the event in the wider context of her life narrative and turning death into a learning experience, the event has been successfully controlled and integrated into successive conceptions of herself.

In contrast to Iris's collapse of temporal boundaries, Fiona discursively constructs temporal limits around the emotional desolation caused by the event. She distances herself from it with the relativising clause 'I was devastated at the time'. This effectively marks the boundaries between past and present and firmly locates the teller and the meanings constructed in the changed location of the present. Fiona also identifies the event as pre-determined with the claim that 'I think she was destined to die right from the beginning but I didn't know that at the time'. This simultaneously integrates the event as an inevitable component of her life story and uses the non-rationalist concept of destiny as a way of refiguring chance as necessity. The fatalism inherent in the concept performs the rhetorical function of absolving any individual of responsibility for the death.

The availability of the experience to be narrated in order to achieve rhetorical ends marks the extract out as painful but ultimately knowable and assimilable. Fiona closes down alternative interpretations of the meaning of the event in her narrative by including references to the criteria for the event to be considered a tragedy (It would be much more tragic if I hadn't [had more children]) and at the same time demonstrates why this event does not meet these requisite criteria. She is concerned not so much with the literal nature of the past event as with the discursive construction of its meaning in the present. It is precisely this interpretative dimension that is absent from Iris's account. Fiona's concern that the interviewer should not cry at the account of her daughter's death (rather than herself, the primary sufferer) acts as a further rhetorical device for legitimating her own subsequent rationale of the event and the conspicuous absence of her own tears. The effect of this is extended to the claim that it would be possible for her to use her experience to assist other people through similar experiences, and to a concern for the interviewer's feelings as a means of closure in the last line of the extract. Indeed, communicatively Fiona manages to convey an estimation of her handling of the experience as exemplary. She has not only reflexively assimilated the experience to her own successive senses of self but also considered the potential ways in which her account may be received and understood by other listeners. Had the episode remained traumatic for Fiona, the experience would not have been available for these rhetorical uses.

Both of the accounts we have sampled involve absence and loss but are articulated in different ways. Iris's account bears more of the discursive features commensurate with the traumatic failure of memory as a sense-making process. In contrast the discursive features of Fiona's account work to perform a more successful remembering of a devastating experience through which she is able to construct a 
temporally continuous identity for herself as a mother, and perform the rhetorical work of situating others in relation to herself. If this represents post-traumatic growth or at least a more successful discursive handling of a potentially traumatic experience, the other account represents a working-through of a woman's suffering that is only partially successful. The traumatic features of her experience are not wholly controlled but continue to haunt the present with a disturbing and strange quality in which, figuratively at least, nothing has changed. This may derive in certain ways from relative class disadvantage, but it would be condescending to elaborate on this without strong supporting evidence. Misery may fall upon anyone's head. In this sense we agree with La Capra that 'the relation between individual and society' should not be 'prejudged on the basis of current ideologies to be purely analogical' but rather seen as 'a problem for inquiry and argument' (La Capra, 1994: 9). Without attending to anyone's relative individuality and collective status in memory's production of (or failure to produce) meaning out of the past, analysis is likely either to be steeped only in the intensely intimate nature of traumatic experience (BenEzer, 2004: 29), or to stay confined in focus on the social and cultural constellation of life experiences that remain anonymous or merely illustrative of a broader collectivity (Rogers and Leydesdorff, 2004: 2 and Erikson, 1994).

\section{Questions of Methodology}

The meaning of past experience is only available for scrutiny at the points at which it is communicated and reconstructed through discourse. The very condition of traumatic experience is the radical inhibition or breakdown of this process. Although life stories remain a key source for gaining an understanding of trauma, the emergence of traumatic accounts during in-depth interviews poses particular methodological and analytical problems. As well as examining the manifest content and form of a narrative account, the problem for discourse analysis is that it has to account for such features as silences, lacunae and sudden narrative shifts. The problem begins with knowing how to respond to traumatic accounts which may at first appear disrupted, elliptical and potentially confused. Worry over their limited value as evidence may lead an interviewer into inappropriate further queries, probes or attempts to help an informant move towards a more conventional narrative mode. Gadi BenEzer specifically identifies thirteen 'communication signals' which indicate that a particular life story features traumatic experience. He provides a framework for interviewers to respond to these kinds of accounts and highlights the importance of empathetic responses to interviewees' accounts. This includes providing them with the discursive space to take control of and account for their experience without interruption or interference (2004: 34-41). By allowing trauma to be communicated by the interviewee without undue interference, and attending as much to points of failure in communicating the experience as to the more conventional accomplishment of narrative construction, we may come closer to understanding how the traumatic experience continues to exert disruption in the present.

Where memory narratives deploy the logic of conventional linguistic and grammatical codes, trauma disrupts the very conventions of communication which 
discourse analysis seeks to recognise. This gives significance to what is not said as well as what is. Although the not-said isn't as readily available for analysis as the sayable and the said, we need to find ways of attending to both so that we can assess the extent to which painful memories have become integrated into successfully told stories involving rhetorical work of various kinds, and those which have not become woven into a lifenarrative and so are not available for such work. Failure to tackle these problems of method and analysis would mean confining our attention only to more conventionally accomplished discourse and to the completed processes of remembering which they represent. It is not just a matter of identifying the specific trauma signals outlined by BenEzer, for several of these are analytically problematic and illustrate the consequences of basing the analysis of accounts of painful pasts on the performance of the interviewee in isolation from their social and cultural context. Self-report, for instance, involves an informant's own assessment of an event as traumatic. The difficulty with this criterion for dealing with trauma signals is that it fails to appreciate the social value of the idea of trauma and the rhetorical ends of self-made experiential claims, in particular that of attaining the 'ultimate authority' which is invested in the position of the victim (Huyssen, 2003: 16). Accounts are evaluated through a particular set of culturalist assumptions and interviewers are themselves repositioned in relation to the teller.

This kind of rhetorical work was a key feature of Fiona's account and central to its meaning both for her and her audience. BenEzer suggests that trauma can be identified by the presence of either too much or too little emotion, yet there are no criteria for judging what constitutes either too much or too little. Who is to say and on what basis? In Fiona's account the limited display of raw emotion has to be interpreted in the context of her confidence in the exemplary quality of her narrative, signalling that the experience is being integrated and deployed in the interests of positioning herself in a particular social role and position, rather than indicating that the experience remained disruptive to her sense of continuing self. In order for the hermeneutic value of the concept of trauma to be effectively realised through its use as an analytical tool, close and systematic attention to discursive features of accounts which situates them in their social and cultural frameworks is crucial.

Only by bringing personal histories into their social and cultural contexts of experience and remembering can we make sense of the communicative limits of traumatic experiences and distinguish them from painful pasts that, despite their subject matter, have been made into effective memory. Analysing individual accounts in their social and cultural contexts allows us to explore 'trauma as a psychic phenomenon ... located on the threshold between remembering and forgetting, seeing and not seeing, transparency and occlusion, experience and its absence in traumatic repetition' (Huyssen, 2003:16). Yet as we have argued throughout, the temptation to make trauma too expansive in reference and scope should be resisted. Painful memories as such are not universally definable as traumatic. In order to distinguish between trauma as unassimilated experience disruptive of the ongoing construction of subjectivity, and memory as self-constitutive, actively interpretative and available for rhetorical purposes, we need more refined criteria for assessing which painful memories are and are not 
traumatic. It is the use and application of trauma in analytical work and the precision with which it is deployed that ultimately determines its conceptual value.

Andreas Huyssen suggests that our understanding of memory would become unduly confined, and marked too exclusively by pain, if read only through the prism of trauma (2003: 17). This is true, and just as distorted as reading history through the experience of trauma. By over-reaching its analytical limits, or by simplistic analogous application to collective experience without reference to due measures of individuation, the explanatory value of trauma as a concept is lost. The concept of trauma need not be confined to clinical discourse, but any uses beyond this need to be carefully defined and elaborated. Freud does not provide the key to a new philosophy of history.

\section{References}

Alexander, J. C. (2004) 'Toward a Theory of Cultural Trauma' in Alexander, J.C., Eyerman, R., and Giesen, B. (eds.) Cultural Trauma and Collective Identity, Berkeley, CA. and London: University of California Press.

Antze, P. and Lambek, M. eds. Tense Past: Cultural Essays in Trauma and Memory, New York and London: Routledge.

Atkinson, R. (1998) The Life Story Interview. California, London, New Delhi: Sage.

Bennett, J. and Kennedy, R. eds. (2003) World Memory: Personal Trajectories in Global Time. Basingstoke and New York: Palgrave Macmillan.

BenEzer, G. (2004) 'Trauma Signals in Life Stories' in Rogers, K. L., Leydesdorff, S. and Dawson, G. (eds) Trauma: Life Stories of Survivors. New Brunswick and London: Transaction.

Bertaux, D. (ed) (1981) Biography and Society: The Life History Approach in the Social Sciences. Beverley Hills and London: Sage.

Bridgers, L. (2005) Contemporary Varieties of Religious Experience, Lanham MD: Rowman and Littlefield.

Caruth, C. ed. (1995) Trauma: Explorations in Memory, Baltimore: Johns Hopkins University Press.

Caruth, C. (1996) Unclaimed Experience: Trauma, Narrative, and History. Baltimore and London: John Hopkins University Press.

Colvin, C. (2003) “"Brothers and Sisters, Do not be Afraid of Me’: Trauma, History and the Therapeutic Imagination in the New South Africa’ in Hodgkin and Radstone. 
Dickens, C. (1965) Great Expectations, Harmondsworth: Penguin.

Elliott, J. (2005) Using Narrative in Social Research. London: Sage.

Erikson, K. (1994) A New Species of Trouble: The Human Experience of Modern Disastors. New York: W W Norton \& Co Ltd.

Felman, S. and Laub, D. (1992) Testimony: Crises of Witnessing in Literature, Psychoanalysis, and History. New York and London: Routledge.

Freud, [1920] (2001) 'Beyond the Pleasure Principle' in Strachey, J. (eds.) The Standard Edition of the Complete Psychological Works of Sigmund Freud: Beyond the Pleasure Principle, Group Psychology and Other Works, London: Vintage.

Gerner, K. (2006) 'Open Wounds? Trianon, the Holocaust and the Hungarian Trauma' in Mithander, C., Sundholm, J., and Holmgren Troy, M. (eds.) Collective Traumas: Memories of War and Conflict in $20^{\text {th }}$ Century Europe. Brussels: Peter Lang.

Hacking, I. (2002) Historical Ontology. Cambridge, Mass. and London, UK: Harvard University Press.

Hodgkin, K. and Radstone, S. eds. (2003) Contested Pasts: The Politics of Memory, London and New York: Routledge.

Huyssen, A. (2003) ‘Trauma and Memory: A New Imaginary of Temporality’ in Bennett, and Kennedy.

Jacobs. J. (2008) 'Gender and Collective Memory: Women and Representation at Auschwitz’, Memory Studies, 1: 2, May, pp. 211-25.

James, W. (1894) 'Professor Wundt and Feelings of Innervation', Psychological Review, 1: 70-3.

Kohler Riessman, C. (1993) Narrative Analysis. California, London, New Delhi: Sage.

La Capra, D. (1994) Representing the Holocaust: History, Theory, Trauma. Ithaca and London: Cornell University Press.

La Capra, D. (1999) ‘Trauma, Absence, Loss’, Critical Enquiry 25(4): 696-727.

La Capra, D. (2001) Writing History, Writing Trauma. Baltimore: Johns Hopkins University Press.

Leydesdorff, S. (1994) How We Lived with Dignity: the Jewish Proletariat of Amsterdam, 1900-1940, Detroit: Wayne State University Press 
Leydesdorff, S., Dawson, G., Burchardt, N., and Ashplant, T. G. (2004) 'Introduction: Trauma and Life Stories' in Rogers, K. L., Leydesdorff, S. and Dawson, G. (eds) Trauma: Life Stories of Survivors. New Brunswick and London: Transaction.

Linde, C. (1993) Life Stories: The Creation of Coherence, New York and Oxford: Oxford University Press.

Luckhurst, R. (2003) ‘Traumaculture’, New Formations, 50: 28-47.

Misztal, B. (2003) Theories of Social Remembering, Maidenhead and Philadelphia: Open University Press.

Neal, A. G. (1998) National trauma and collective memory: Major events in the American century. New York and London: M E Sharpe.

Plummer, K. (1983) Documents of Life. London: Allen \& Unwin.

Radstone, S. (2005) 'Reconceiving Binaries: the Limits of Memory', History Workshop Journal, 59, 2005: 134-50.

Tal, K. (1996) Worlds of Hurt: Reading the Literatures of Trauma, Cambridge and New York: Cambridge University Press.

Wodak, R. (1986) Language Behaviour in Therapy Groups. Berkeley: University fo California Press.

Wodak, R. (1996) Disorders of Discourse. London: Longman.

Zylinska, J. (2005) The Ethics of Cultural Studies, London and New York: Continuum. 